\title{
Pressor Unit per Milliliter
}

National Cancer Institute

\section{Source}

National Cancer Institute. Pressor Unit per Milliliter. NCI Thesaurus. Code C73577.

The activity of a pressor agent expressed in pressor units per milliliter. 